tracted from the anthropometric radius of the segment to determine the radius of the inner cone of muscle and bone. The differences in the percentage fat measured by the two techniques were then compared. It was found that the estimation of percentage fat calculated by the ultrasound method in both segments was significantly higher $(\mathbf{P}<0.01)$ than the method which measured the circumference by direct means (see table 4 , reference 1 , our original paper).

We therefore acknowledged the potential difference in absolute scores obtained by the two procedures. Importantly, however, it was found that the percentage fat measurements in both segments correlated highly $(0.92$ and above) and that the ultrasound estimation of percentage fat at the thigh was the best predictor of overall percentage body fat in both groups.

We also stated that further research should be conducted on the use of these procedures. If we were to repeat the study we would recommend that the level of agreement should also be explored by the methods recommended by Bland and Altman, ${ }^{3}$ which is more sensitive to assessing agreement between two methods of measurement. However, this is a matter of statistical procedure rather than technical methodology.

In summary, our method for determining the proportions of lean and fat components using a cone model in the thigh is sound and permits a reasonably accurate volumetric assessment of percentage adipose tissue.

$$
\begin{array}{r}
\text { ROGER G ESTON } \\
\text { Senior Lecturer } \\
\text { Human Physiology } \\
\text { University of Wales, Bangor } \\
\text { RHODRI EVANS } \\
\text { Consultant Radiologist } \\
\text { Morriston Hospital, Swansea }
\end{array}
$$

1 Eston RG, Evans R, Fu F. Estimation of body composition in Chinese and British men by ultrasonographic assessment of segmental adipose tissue volume. Br F Sports Med 1994;28:9-

2 Jones PRM, Pearson J. Anthropometric determination of leg fat and muscle plus bone volumes in young male and female adults. F Physiol 1969;204:63-6.

3 Bland JM, Altman DG. Statistical methods for assessing agreement between two methods of clinical measurement. Lancet 1986;i:307-10.

\section{Injury in rugby league football: the new super league}

EDITOR,-Previous research has suggested that the injury rate in rugby league is higher than in most other team sports. ${ }^{1}$ Nineteen ninety six saw the game move its competitive season to the spring and summer months of the year. This resulted in changes in playing conditions, higher temperatures, and harder surfaces, but the playing season had about one third fewer games.

Preliminary analysis of our data from the first team of two professional rugby league clubs (one Super League, one First Division) indicates that the injury rate was 53.9 injuries per 1000 hours of play (95\% CI 37.9 to 70.0 ); an injury being defined as a condition that occurred during match play requiring a player to miss the next competitive game. This is equivalent to a team receiving an injury every 86 minutes of match play. There were no significant differences in the rates between the two clubs (super league 50.3 (95\% CI 28.8 to
71.8) per 1000 hours of play, first division 57.9 (95\% CI 33.8 to 82.0 ) per 1000 hours of play).

These injury rates are higher than have previously been reported for winter rugby league in England (34 per 1000 hours of play) ${ }^{2}$ and in Australia (45 per 1000 hours of play). ${ }^{3}$ Within the limitations of a cross sectional study such as this, these preliminary findings indicate that the introduction of summer rugby has increased the risk of injury. Whether this is actually due to the change in playing conditions, or to other factors, should be the subject of future research. This finding has implications for players, coaches, and sports medicine practitioners.

CONOR GISSANE Department of Health Studies Brunel University College Isleworth

LISA H PHILLIPS Department of Orthopaedic and Accident Surgery Queen's Medical Centre Nottingham DEANNA JENNINGS General Practitioner Reigate, Surrey JOHN WHITE

Department of Public Health Medicine and Epidemiology

Queen's Medical Centre
Nottingham

ANGELA CUMINE

Department of Sport Science and PE St Mary's University College Twickenham

1 Seward H, Orchard J, Hazard H. Football injuries in Australia at the elite level. Med $\mathcal{F}$ Aust ries in Australia at

2 Stephenson S, Gissane C, Jennings D. Injury in rugby league: a four year prospective survey. $\mathrm{Br}$ f Sports Med 1996;30:331-4.

3 Gibbs N. Injuries in professional rugby league: a three year prospective study of the South Sydney professional rugby league football club. Am $\mathcal{F}$ Sports Med 1993;21:696-700.

\section{BOOK REVIEWS}

Usage of Sports Medicine Clinics in Scotland. Final Report to the Scottish Sports Council. By A Nielsen and R Knill-Jones. (Pp 120; soft cover; colour copy $£ 35$.$) Scottish Sports Council, 1997$.

Public health and The Health of the Nation have encouraged physical activity in all ages. Increased sporting activity will result in an increase in sports related injuries. No provision has been made for this in primary or secondary care. Over the past 10 years sports injury clinics have been set up in Scotland to treat chronic/recurrent sports related injuries at a primary care level. This excellent descriptive study of attendance at these clinics in Scotland adds considerably to the body of knowledge of sports related injuries and gives some indication of the need that exists.

This is the largest descriptive study of chronic/recurrent sports related injuries in the
United Kingdom and the second largest such study world wide. Data are presented from chronic/recurrent injuries related to sporting activities from 18 out of 26 sports medicine clinics in Scotland supported by the Scottish Sports Council and by the Scottish Institute of Sports Medicine. Data were collected between 1990 and 1995 by standard record card completed, firstly, by the patient and then by the doctor or physiotherapist. The data in the final report give a detailed breakdown of 9487 attendances at 18 sports medicine clinics.

Data are extensive and extremely well presented in table and graphic form. They are available on referrals, type of injury, age groups, social class, time since injury, follow up, recovery rates, height and weight, numbers who warm up and warm down, time off work following injury, and injuries in children All of these categories are broken down into sports giving a detailed in-depth analysis of sports related injuries. With these tables the most common injuries can be identified in each sport.

Published sports participation data are used to compare sports and to produce a table of injuries per 1000 participants in each sport. These data are presented in a league table of sports, with athletics, rugby, hockey, and skiing at the top and cycling, dancing, aerobics, and swimming at the bottom, with other sports in between. This is fascinating reading but must be interpreted with caution owing to the extrapolation of the data.

Evidence of the high quality of this descriptive study is found in the comparison of the results relating to rugby injuries with a cohort study of rugby injuries funded by the Scottish Rugby Union (Garraway and Macleod, 1995). The results show reasonable consistency between the two studies for age, timing of injuries during the season, type of injuries, and time off work or sport. The consistency of results with a cohort study strengthens the value of this descriptive study.

No details are given about how these clinics are advertised. Considering that these clinics offer treatment at a primary care level it is surprising that only $8.5 \%$ of patients are referred by general practitioners and that only $24 \%$ of GPs refer to the clinic at all. Self referrals account for $59.6 \%$ of the attendances

This report is an essential read for anyone involved in planning or providing a primary care type service for chronic or recurrent sports related injuries. The data available in this report will be useful not only in the treatment of injuries but also in prevention. The clear evidence of marked differences between sports highlights the need to prevent injury and to treat injury effectively. The study is now considering the need to increase awareness of risk factors and improve treatment by a structured dissemination of the information found in this report. Short reports with information relevant to individual sports will be sent to individual sports associations. The report also proposes to disseminate information to Scottish GPs.

With the possibility that a new Bill on Primary Care will enable funding of pilot projects in practices from April 1998 there may be an opportunity to improve the treatment of chronic sports related injuries at a primary care level. The information provided in this report would be essential to any practice applying to their health authority for funding .

DAVID RUSSELL 